\title{
WHEN REGIONAL ANESTHESIA ISN'T AN OPTION Management of a pregnant patient with Marfan's Syndrome
}

Pato, $R^{1}$; Figueiredo, J. ${ }^{2}$, Rocha, T. $^{3}$

Central Lisbon University Hospital Center

Anestesiology Director: $\mathrm{Dr}^{\mathrm{a}}$ Isabel Fragata

\section{BACKGROUND}

Marfan Syndrome (MFS) is a genetic disorder caused by mutation in the FBN-1, witch causes changes in the development of structure and flexibility of the connective tissue. According with the Berlin Nology of 1986, this patients usually have cardiovascular, pulmonary and eyes pathology, chest wall and vertebral deformities (pectus carinatum and mild to severe scoliosis) and specific phenotypes as arachnodactyly, high arched palate, tall stature and long members. The most frequent clinical findings are aortic aneurisms, ectopia lens and severe scoliosis. The anaesthetic management for caesarean section in parturient with MFS is a true challenge, not only for the cardiovascular risk but also because of difficulties associated with neuraxial approach, that could jeopardize the security of the fectus.

\section{CASE DESCRIPTION}

§, 27 years old, OI 0000, proposed to Caesarean Section at 38 weeks of pregnancy

Past medical history: Marfan syndrome diagnosed at 16 years old, mild aortic insufficiency, severe scoliosis, anxiety.

Past surgical history: Orthopaedic foot surgery (2006) Dorso-lombar vertebral instrumentation (2009), Hallux valgus correction (2012). All 3 accomplished with Balanced General Anaesthesia, with no complication's registries. None allergies.

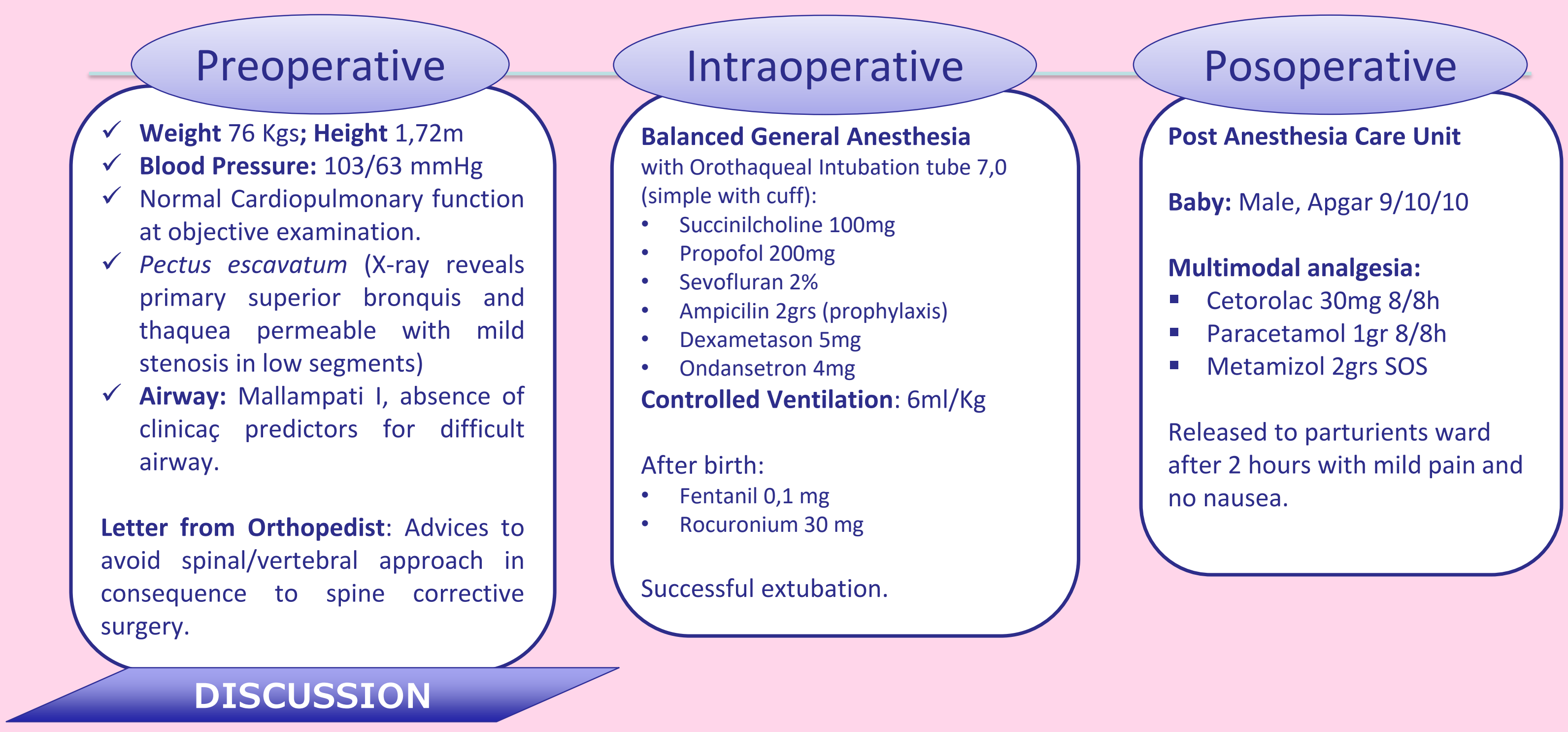

Neuroaxial anestesia is the gold standart for C- section and labour in any pregnant women. Women with MFS commonly have cardiovascular pathology, more frequently valvular insufficiency and aorta dilation as a consequence of excessive laxity of connective tissue, being preferable regional to general anaesthesia. However, skeletal deformities is also a characteristic of MFS patients, mainly vertebral scoliosis at a severe level, leading to the need of surgical correction at early age with metal osteosynthesis material attachment. In this future moms, this surgery will make que approach of neuraxial anaesthesia for labour or C-section very difficult or even impossible.

Perioperative management of parturients with MFS also include cardiopathy prophylaxis and careful airway planning, because of deformation of dental arcade and incisive prominence rising the probability of difficulties on airway approach in orotraqueal intubation.

\section{CONCLUSION}

Although regional anaesthesia is the gold standard for C-section, parturients with MFS should have a careful anesthetic plan, considering cardiovascular and skeletal abnormalities that could be a relative contraindication for neuraxial blockage. 